\title{
Lexicografía académica, hispanismo y dictadura: el Diccionario del habla chilena (1978) de la Academia Chilena de la Lengua
}

\author{
Academic Lexicography, Hispanism and Dictatorship: the Diccionario \\ del habla chilena (1978) of the Chilean Academy of the Spanish Language
}

\author{
DARío RoJAs [darioroj@uchile.cl] \\ Universidad de Chile, Chile
}

\begin{abstract}
RESUMEN
En este trabajo ofrecemos una lectura glotopolítica del Diccionario del habla chilena (1978) de la Academia Chilena de la Lengua, complementaria a algunos análisis metalexicográficos que se han hecho hasta ahora. Profundizamos en la historicidad de este diccionario identificando tanto su relación con la tradición lexicográfica chilena en que se inscribe como con su contexto material de producción. El contexto de preparación del VII congreso de academias en 1976 y la campaña de legitimación exterior de la dictadura militar chilena de Pinochet desde 1973 movilizan las ideas e intereses del hispanismo, que se reflejan tanto en las intervenciones glotopolíticas asociadas a la elaboración del diccionario como en la representación ideológica de la lengua que contiene.
\end{abstract}

\section{Palabras Clave}

Glotopolítica; lexicografía crítica; academias de la lengua; diccionarios de español; español de Chile

\begin{abstract}
In this work we offer a glottopolitical reading of the Diccionario del habla chilena (1978) of the Chilean Academy of the Spanish Language, complementary to some metalexicographic analyzes that have been done so far. We delve into the historicity of this dictionary, identifying both its relationship with the Chilean lexicographical tradition to which it belongs and with its material context of production. The context of preparation for the 7th Congress of Academies in 1976 and the foreign legitimization campaign of the Chilean military dictatorship of Pinochet since 1973 mobilized the ideas and interests of Hispanism. These ideas and interests can be observed as much in the glottopolitical actions associated with the creation of the dictionary as in the ideological representation of language it contains.
\end{abstract}

\section{KEYWORDS}

Glottopolitics; critical lexicography; language academies; Spanish dictionaries; Chilean Spanish

\section{RECIBIDO 2020-05-22; ACEPTADO 2020-07-31}

Este trabajo se inscribe en la investigación postdoctoral "En los bordes de la lengua: actitud e ideología lingüística en Andalucía y Chile (1850-1950)", financiada por el programa de Becas de Postdoctorado en el 
Extranjero - Becas Chile, convocatoria 2019, de ANID (ex CONICYT). El rescate patrimonial e investigación preliminar de las actas de la Academia Chilena se realizó en el marco del proyecto FONDART 439977 (www. actasachl.cl). Agradezco especialmente a Valentina Cáceres por el trabajo de transcripción de las actas del periodo $1975-1976$.

\section{Introducción}

En su periodización tentativa de la lexicografía diferencial monolingüe del castellano de Chile, Matus (1994) proponía distinguir:

(1) una etapa precientífica, que transcurría desde 1875, cuando se publica el primer diccionario de chilenismos (Rodríguez 1875) hasta 1918, en que termina de aparecer la obra de M. A. Román (1901-1918);

(2) una etapa de transición, representada por el Diccionario del habla chilena de la Academia Chilena de la Lengua (en adelante, $\mathrm{DHCh}$ ), publicado en 1978; y

(3) una etapa científica, en la que se inscribían solo (hasta la fecha de escritura del texto de Matus) el Diccionario de chilenismos y otros usos diferenciales de Félix Morales Pettorino y sus colegas (Morales Pettorino y Quiroz. 1983-1987) y el por entonces todavía vigente proyecto de hacer una versión chilena de los diccionarios contrastivo-diferenciales de la Escuela de Augsburgo (cf. Rojas 2015).

El criterio principal que deslinda claramente las etapas (1) y (3), según Matus, es la cientificidad ${ }^{1}$ de la actividad lexicográfica, ausente en (1) y presente en (3). La presencia de esta característica está en última instancia determinada por el objetivo de las obras: prescribir el buen uso en (1), describir el uso en (3), y las características de los lexicógrafos: autoría individual de intelectuales sin especialización en filología o lingüística, en (1), frente a autoría preferentemente colectiva de lingüistas entrenados según los parámetros actuales de la disciplina, en (3). El DHCh es concebido por Matus como una obra de transición entre (1) y (3) por el hecho de que presenta diferencias importantes respecto de los diccionarios de (1): el foco se desplaza desde la prescripción a la descripción, la autoría es colectiva y no individual y su equipo de trabajo estuvo integrado, en parte (minoritaria), por profesionales del estudio científico del lenguaje.

En el presente trabajo, mi propósito es hacer una contribución a la historiografía de la lexicografía chilena, específicamente en lo relativo al problema teórico-metodológico de la temporalidad, entendida no en términos de la cronología o la periodización de una serie de diccionarios, sino de su historicidad, es decir, su relación dinámica con el contexto material de producción. En consecuencia, a diferencia de la opción de Matus (1994) por identificar el DHCh como representante exclusivo de una etapa de transición entre una etapa "precientífica" y otra "científica", propongo una aproximación historiográfica que entienda el devenir de la lexicografía chilena monolingüe

1 La aplicación de este criterio es en sí cuestionable, primero, por conllevar una lectura y valoración de las obras lingüísticas del pasado en función de expectativas del estado actual de la disciplina (de hecho, es evidente que subyace la discutible presunción de que la historia de la disciplina avanza de lo precientífico a lo científico); y segundo, por implicar la posibilidad de que el discurso lexicográfico pueda ser "verdadero", o políticamente aséptico por quedar libre de ideología o de influencia del contexto. 
en castellano como un continuo, en donde cobran relevancia principal las continuidades/mutaciones de las intervenciones y proyectos glotopolíticos y la relación dinámica de los discursos con sus contextos, en lugar de proponerse la delimitación de "periodos" discretos e internamente homogéneos. Esto justifica, como podrá verse a lo largo del artículo, desplazar la atención de forma predominante hacia fuera del texto mismo del diccionario y poner énfasis primario en el contexto de producción, en particular en los actores sociales relevantes y sus intervenciones glotopolíticas concomitantes a la representada específicamente por el $\mathrm{DHCh}$.

Siguiendo estos lineamientos teórico-metodológicos, propongo, a partir del estudio de diversas fuentes documentales ${ }^{2}$, que el $D H C h$ puede entenderse mejor como intervención glotopolítica si se lo pone en relación con el contexto de la dictadura militar chilena de 1973-1990 y con el congreso de academias de la lengua que se celebró en Chile en 1976 (evento funcional para la legitimación de la dictadura, como veremos), así como si se pone foco en su relación de continuidad dinámica con la matriz inicial de la lexicografía chilena monolingüe en castellano, marcada por el normativismo y la hegemonía del hispanismo, centrales en la gestación de la institución que dio origen al $\mathrm{DHCh}$, la Academia Chilena de la Lengua.

De modo más general, con este trabajo aspiro a enriquecer la comprensión historiográfica del DHCh y la historia de la lexicografía chilena apartándome del enfoque estrictamente metalexicográfico ${ }^{3}$ con el que ha sido hasta ahora estudiada esta obra (Matus 1994; Sáez Godoy 1982 y 1987-1988) para levantar una lectura desde el enfoque de la glotopolítica (Del Valle 2017). Este ofrece la posibilidad de estudiar de forma crítica la inscripción socio-histórico-política de la comunicación lingüística y de las reflexiones metalingüísticas, sean estas pertenecientes o ajenas a lo que hoy llamamos "lingüística". Se entiende pues, desde este enfoque, que indepediente del momento histórico y de las características de los enunciadores, el discurso lexicográfico (como todo discurso, metalingüístico o no) siempre responde a y es configurador de su contexto de producción, de modo que resulta imprescindible dilucidar el entramado de intereses económicos, proyectos políticos, ideologías, etc. que posibilitan que un determinado diccionario se publique en un determinado momento y contexto (cf. Huisa 2013; Lauria 2011; Rodríguez Barcia 2016; y Chen 2019, entre otros, para aproximaciones al estudio de los diccionarios en esta misma línea).

2 Véase la lista de fuentes primarias en la bibliografía. Consideramos como tales: las actas inéditas de las sesiones de la Academia Chilena entre 1885 y 1995, de las cuales resultaron relevantes sobre todo las del periodo 1969-1976, es decir, alrededor de 150 documentos (las citamos en adelante como "acta de sesión AChL", indicando además la fecha de la sesión); artículos de prensa publicados en la prensa chilena en 1976 con ocasión del congreso de academias, de los cuales solo uno resultó informativo respecto del problema; la crónica de la institución de Araneda Bravo (1976), que sirve de complemento al material de las actas; y, por último, el texto mismo del $\mathrm{DHCh}$, específicamente su prólogo, que es donde hay información de mayor valor desde el punto de vista del objetivo del presente trabajo.

3 Es sabido que el análisis de los aspectos estrictamente lexicográficos del diccionario, tales como los criterios de inclusión/exclusión de vocabulario, prácticas de definición, etc., a menudo logra develar los compromisos ideológicos de los autores, como bien ha mostrado una importante tradición de estudios de la lexicografía española representada, entre otras, por Calero Fernández (1999), Forgas (2011), Rodríguez Barcia (2008) y San Vicente et al. (2011). Sin embargo, la opción de excluir del presente trabajo dicha dimensión del análisis se debe, por un lado, a que ya ha sido parcialmente abordada (véase las referencias indicadas arriba) y, por otro, a que incrementaría sustancialmente la extensión del artículo, además en un sentido no del todo provechoso para los fines y naturaleza de esta investigación. 


\section{Los orígenes del $\mathrm{DHCh}$}

\subsection{Bello y la formación de una comunidad discursiva hegemónica}

La llegada de Andrés Bello a Chile en 1829 supuso el inicio de la articulación de una comunidad discursiva gestada en torno al interés común de las clases dominantes por la preservación de la unidad panhispánica de la lengua castellana a través de la defensa de un estándar basado en el habla de las personas cultas, los modelos de la literatura castellana y la autoridad de la RAE (cf. Rojas 2017, para un panorama general). El conjunto de prácticas e ideologías lingüísticas que sustentaron esta comunidad se convirtieron en ideología dominante (Bourdieu y Boltanski 2009) en buena medida gracias al lugar hipercentral que Bello y sus epígonos ocuparon en el campo cultural chileno de todo el siglo XIX, y también gracias a que este proyecto cultural era funcional al orden político conservador instaurado con la Constitución de 1833.

En términos glotopolíticos, la hegemonía del imaginario bellista, vigente hasta bien entrado el siglo XX, se puede explicar por su utilidad para legitimar la posición privilegiada de la clase dominante y al mismo tiempo construir un sujeto subalterno cuya diferencia (lingüística) se traducía en déficit y cuya agencia, por tanto, debía ser delegada en "cuerpos de sabios" capaces de conducir de forma solvente la construcción de la República. Si por un lado la política lingüística hegemónica promovía el uso de un estándar panhispánico castellanizante, su otra cara fue la denostación e intento de supresión de las características dialectales propias del castellano chileno, que lo apartaban de aquel estándar y amenazaban la unidad del idioma.

De esta forma, proliferaron los instrumentos lingüísticos de carácter disciplinatorio, destinados a extirpar del habla de la ciudadanía chilena los usos "incorrectos" (es decir, los dialectales y populares, que amenazaban la unidad idiomática) y enseñar la forma "correcta" de hablar. La primera obra metalingüística de Bello en Chile, sus "Advertencias sobre el uso de la lengua castellana en Chile" (publicadas entre 1833 y 1834 en la prensa), cumple de manera ejemplar esta función, así como lo hace su Gramática de la lengua castellana de 1847, aunque quizá de manera menos transparente (cf. Moré 2014). Uno de los principales tipos de instrumentos lingüísticos que sirvieron para este propósito fueron los diccionarios que se proponían inventariar "chilenismos", entendidos en principio como usos incorrectos, y a la vez ofrecer a los lectores una alternativa castiza para evitar incurrir en ellos (cf. Rojas 2010 para una caracterización de su dinámica discursiva).

\subsection{La Academia Chilena y su misión lexicográfica}

Por otra parte, debemos tener en cuenta que hacia finales del siglo XIX ocurre la institucionalización de la intervención estatal en asuntos del lenguaje mediante la fundación de, primero, en 1885, la Academia Chilena correspondiente de la Española, y luego, en 1889, el Instituto Pedagógico de la Universidad de Chile. La Academia Chilena puede considerarse como la continuación institucionalizada de la comunidad discursiva articulada en torno al pensamiento bellista en el país durante el siglo XIX (Rojas 2016). En su fundación intervinieron dos factores principales: primero, la iniciativa de creación de Academias americanas correspondientes de la RAE, impulsada desde 1870 (Süselbeck 2014), y, segundo, la afinidad política de aquella comunidad discursiva bellista 
con el proyecto neocolonial del hispanismo (Rojas 2019). Gracias al estímulo del académico colombiano José María Samper, en junio de 1885 la Academia Chilena inició sus actividades, en una breve primera etapa que concluyó en 1888 aproximadamente, debido al inestable clima político del país. Tan solo en 1914 la institución retomó su funcionamiento hasta el día de hoy.

Desde un comienzo la actividad de la Academia tuvo en su centro las labores lexicográficas. Tal como exigía su condición de correspondiente y colaboradora de la RAE, la Academia Chilena se propuso entre sus primeras tareas la de colaborar con la elaboración del por entonces todavía llamado Diccionario de la lengua castellana, hoy (y desde 1925) Diccionario de la lengua española. Por 1885, acababa de publicarse la edición número 12 de esta obra y comenzaba a prepararse la siguiente, que saldría en 1899. Probablemente se sentía en Madrid la necesidad urgente de tomar cada vez más en cuenta las variedades americanas de la lengua castellana, debido, por un lado, al proyecto en marcha de establecer una red de academias americanas correspondientes (cf. supra), y, por otro, por el desafío comercial que le había presentado el Nuevo diccionario de la lengua castellana de Vicente Salvá, publicado en París en 1846, que sobresalía precisamente por la abundancia de americanismos y su gran éxito en América.

En una de las actas de las sesiones iniciales de la corporación figura la primera mención explícita de la tarea lexicográfica primordial de la Academia Chilena:

Pasóse en seguida a fijar la materia de los trabajos que, para cumplir con los fines de la institución, habria de acometer la Academia i, despues del correspondiente debate, se acordó que desde la sesión próxima i tomando por base las Apuntaciones que sobre algunas palabras usadas en Chile, especialmente en el lenguaje legal i forense, ha estado publicando el Señor Don Miguel Luis Amunátegui i el Diccionario de Chilenismos escrito por el Secretario, se emprenderia un estudio ordenado i tan completo como fuese posible, no solo de los provincialismos chilenos o peculiaridades de nuestra habla, sino tambien del Diccionario jeneral de la lengua, para elevar a la consideración de la Real Academia Española las observaciones que el último por ella publicado sujiriese, a fin de que aquel Docto Cuerpo pueda tomarlas en cuenta en la próxima edición que haga de tan importante obra. (Acta de sesión AChL, 01/08/1886)

En la cita precedente puede verse además que el trabajo lexicográfico de colaboración con la RAE fue pensado como una continuación o proyección de los trabajos lexicográficos que los miembros fundadores de la Academia Chilena venían realizando desde hace ya varios años con el mismo fin, entre ellos el Diccionario de chilenismos de Zorobabel Rodríguez (1875), primer secretario de la corporación. Además de ser la obra más representativa del tipo de trabajos lingüísticos en que se fundamentó la acción lexicográfica de la Academia en sus inicios, Rodríguez (1875) es el primero de una tradición de obras similares que se prolongó hasta bien entrado el siglo XX, entre las cuales sobresalen Ortúzar (1893) y Román (1901-1918), todas de autoría de miembros de número o correspondientes de la Academia Chilena y todas ellas influyentes, en mayor o menor grado, en la incorporación de voces chilenas en las ediciones correspondientes del diccionario de la RAE.

Si bien la Academia Chilena durante sus primeros años y hasta la primera mitad del siglo XX se concentró en colaborar con el Diccionario de la lengua castellana o española, mientras sus miembros publicaban a título individual diccionarios normativos consagrados a denunciar los 
chilenismos y otros "vicios" idiomáticos, ya por la segunda mitad de la década de 1960, según muestran las actas de la corporación, empezó a trabajar con entusiasmo en un proyecto de Diccionario de chilenismos de autoría institucional, que tiene origen en la misión primordial de la Academia declarada en 1886, y que a su vez constituye el germen del $\mathrm{DHCh}$.

\subsection{El proceso de creación del $\mathrm{DHCh}$}

La cronología del trabajo de elaboración del DHCh fue más o menos la siguiente. De acuerdo con la información de las actas de la Academia Chilena, el proyecto se puso en funcionamiento efectivo por 1967, cuando distribuyó entre los académicos el trabajo por letras del diccionario. El impulso inicial de esta etapa se debió a Alejandro Garretón Silva, según Araneda Bravo (1976: 79). En agosto de 1969, las actas indican que "pasó a ocuparse la Academia de las Recomendaciones que deberán tenerse presentes en la composición del Diccionario de Chilenismos" ". Estas recomendaciones constituían una especie de protoplanta lexicográfica, redactada por Rodolfo Oroz, que indicaba:

El material lexicográfico se basará en:

1. Los Chilenismos que figuran como tales en la edición $18^{\circ}$ del Diccionario de la Real Academia.

2. Los Chilenismos que figuran como tales en el Diccionario Manual e Ilustrado de la Lengua Española $2^{\circ}$ ed. 1950 y también los publicados en los Boletines Oficiales de la Real Academia y Comisión Permanente.

3. Los vocablos y expresiones que se hallan en las obras nacionales sobre chilenismos y que no figuran en el Diccionario de la Real Academia.

4. Los chilenismos que figuran como tales en los diccionarios de americanismos (Malaret, Santa María, Morínigo) aunque no aparezcan en el Diccionario de la Real Academia.

5. Las voces y expresiones no recogidas por los diccionarios pero de uso corriente en Chile.

4 Desde 1971, en el pleno hubo varias discusiones acerca del título más conveniente para el diccionario, hasta entonces llamado siempre "de chilenismos". En la sesión del 15/11/1971, que se dedicó exclusivamente a este asunto, el director Oroz propuso llamarlo Diccionario del habla chilena, lo que fue aprobado por el pleno, a pesar de que otros académicos (Augusto Iglesias y Arturo Aldunate) se inclinaban por Diccionario del habla de los chilenos. Ya por 1975 en las actas figura como Diccionario del habla del pueblo de Chile, pero al informar la comisión encargada sobre su estado de avance la atención se vuelca sobre el título, específicamente sobre los “inconvenientes" de llamarlo de esa forma (17/03/1975), en virtud de los cuales se plantea la posibilidad de volver a alguno de los títulos originales. Aunque las actas no registran el detalle de cuáles fueron los "inconvenientes" puestos sobre la mesa, se puede presumir que tenían que ver con la connotación política que el término pueblo conllevaba en el contexto inmediatamente posterior al gobierno socialista de la Unidad Popular, carga de la que probablemente los académicos no deseaban hacerse responsables o con la que derechamente no comulgaban. En las reuniones siguientes de la Comisión de Lexicografía se optó por el título que finalmente llevaría en la imprenta, "porque representa mejor que otros, el vocabulario usado consi[st]entemente en Chile" (acta de sesión AChL, 07/04/1975). En la versión publicada del DHCh, se justifica el abandono del concepto de chilenismo y la preferencia por el título final en razón de "que no ha llegado todavía el momento de decidir con alguna certeza lo que es realmente 'propio y exclusivo de Chile', en el uso de vocablos o giros que caracterizan nuestra lengua" (Academia Chilena 1978: 17), lo cual puede leerse al mismo tiempo como un intento de distanciarse de la tradición lexicográfica chilena normativista, que habitualmente usó aquel concepto, y que además usualmente concibió el chilenismo como error o desviación (cf. Rojas y Avilés 2014). Por otra parte, en 1953 Ambrosio Rabanales (en su tesis doctoral, dirigida por Rodolfo Oroz) había llamado la atención sobre la necesidad de determinar con precisión qué debía entenderse por chilenismo antes de hacerlo operativo en la lexicografía (cf. Ayala 2011), a partir de lo cual el concepto empezó a revestirse de connotaciones más bien dialectológicas. 
6. Los vocablos y expresiones de uso corriente en Chile que se dan también en otros países hispanoamericanos.

Nota. Se registraron las variantes de voces de origen indígena tales como "chalala", "chalaila" y otros cuya ortografía es vacilante, por ejemplo "guaso" y "huaso".

En cambio no se incluirán variantes fonéticas de vocablos españoles tales como "madestro" por "maestro", "pior" por peor, "paire” por padre. (Acta de sesión AChL, 18/08/1969)

Durante esos últimos años de la década de 1960 la Academia trabajó con periodicidad en su diccionario (en prácticamente todas las sesiones se discutieron algunos puñados de voces, en algunas de ellas de forma exclusiva). En esta etapa temprana, se realizó un trabajo colectivo de discusión de voces en las sesiones del pleno, en el que se involucró una amplia gama de académicos, como revela la distribución de letras para el trabajo (acta de sesión AChL, 19/03/1968). Tan solo en 1970, tal como indica el "Prólogo" del DHCh y corrobora el acta del 02/03/1970, "a pedido del académico Sr. [Yolando] Pino se constituyó la Comisión de Lexicografía encargada de realizar el proyecto de publicar un Diccionario de Chilenismos", integrada por el director Oroz como presidente, el secretario Lira en cargo homólogo, y los académicos Yolando Pino, Raúl Silva Castro (quien moriría solo tres meses después de constituirse el equipo) y Alejandro Garretón Silva ${ }^{5}$.

Esta comisión, de forma novedosa, celebraría sesiones de trabajo independientes de las sesiones del pleno (aunque todas sus propuestas luego deberían ser aprobadas por el pleno), y contaría además con un ayudante técnico (nunca identificado en las actas) encargado de "reunir y ordenar las fichas de chilenismos y presentarlas oportunamente a la Comisión" (acta de sesión AChL, 02/03/1970). Al grupo original se irían sumando el historiador Eugenio Pereira Salas (a quien desde 1971 se lo puede ver muy activo en la presentación de propuestas lexicográficas en el pleno, representando a la comisión), y, más tardíamente, a medida que se incorporaban como miembros de la Academia, el escritor y diplomático Javier Vergara Huneeus (1974), el aviador y escritor Diego Barros Ortiz (1975), y los miembros correspondientes Hugo Gunckel y Alfredo Matus, ambos incorporados en 1975 y de perfiles altamente especializados en sus respectivas disciplinas: botánica y lingüística ${ }^{6}$.

5 De esta comisión original, solo Oroz tenía una importante experiencia técnica en lexicografía, disciplina que, por lo demás, por entonces todavía no se concebía como necesariamente especializada. Oroz, además de tener formación profesional de latinista y filólogo y reconocidas credenciales en el ámbito disciplinar de los estudios del lenguaje, ya contaba con la experiencia de haber sido autor del Diccionario de la lengua castellana, publicado por primera vez en 1943 por la editorial chilena Zig-Zag con el título Nuevo diccionario de la lengua castellana, y que corresponde a un sucedáneo del diccionario de la RAE. Yolando Pino, folklorólogo y con formación filológica, en 1968 había sido delegado de la Academia Chilena en la Comisión Permanente en Madrid, estancia durante la cual se involucró en los trabajos del DRAE. Pedro Lira, por su parte, tan solo por esos mismos años en que se preparaba el DHCh publicó un par de obras pertinentes: Vocablos académicos y chilenismos (1969), que consiste en un análisis de voces admitidas por la RAE y que no alcanzarían a figurar en la próxima edición de su diccionario, y Estudios de vocabulario (1973). Ambas obras de divulgación reunían breves artículos publicados en el diario santiaguino El Mercurio entre 1969 y 1972, que tratan sobre todo de enmiendas, adiciones y supresiones de chilenismos en el DRAE, así como intentan mostrar al público cómo se hace el trabajo lexicográfico académico. Solo Raúl Silva Castro, periodista y crítico literario, y Alejandro Garretón Silva, médico y ex ministro de Educación, carecían de experiencia alguna en la elaboración de diccionarios de lengua.

6 En el caso de Gunckel, sus aportes se dieron a propósito de los términos que requerían de conocimientos sobre ciencias naturales (fue relator de una comisión de términos técnicos integrada también por Arturo Aldunate Phillips). En el caso de Matus, en 1975 acababa de regresar de cursar estudios de posgrado en lingüística en Alemania; se trataba, entonces, del único, además de Oroz, con formación especializada y perfil profesional directamente relevante para la 
Según revela el acta de sesión del 10/12/1973, por ese entonces se lo empezó a pensar como una contribución para el Congreso de Academias de 1976, que se celebraría en Santiago de Chile (se pretendía obsequiar el diccionario a los académicos delegados de otros países, según Araneda Bravo 1976: 80; véase también la "Cronología" de 1973-1974 adjunta al acta de reunión del 05/06/1975, en que se informa que este diccionario se preparaba "como nuestro aporte para el VII Congreso de Academias"), y se planeó inicialmente publicarlo en 1975, con ocasión además del primer centenario de Rodríguez (1875).

A partir de diciembre de 1973, entonces, el trabajo se intensificó para cumplir con el calendario editorial previsto. Por comienzos de 1975, la Comisión de Lexicografía informa que "se han catalogado cuatro mil voces y se cree que serán cinco mil" y que se ha encomendado a Oroz redactar el prólogo (acta de sesión AChL, 17/03/1975). Que el trabajo se venía acelerando cada vez más ante la inminencia del plazo queda demostrado por el hecho de que "entre el 17 y el 31 de marzo, hubo cinco reuniones" de la comisión de Lexicografía (acta de sesión AChL, 07/04/1975). Poco más de un año después, ya habiéndose incumplido el calendario original, se informa que "antes del 15 entraría en prensa" (acta de sesión AChL, 07/06/1976). En agosto de ese año, a tan solo unos meses de celebrarse el congreso de academias, la comisión entrega un informe detallado de las últimas novedades:

El Dr. Garretón dio cuenta de que con la intervención del Presidente del Instituto de Chile, D. Juvenal Hernández, la Editorial Universitaria aceptó muy honrada, publicar el "Diccionario del Habla Chilena”. Se regalará el papel y se entregarán diez mil pesos. La diagramación de corte clásico la hizo el Sr. Mauricio Amster. De los primeros mil ejemplares se regalarán cien a la Academia. De la segunda edición, la Editorial dará, además, a la Corporación el 10\% de venta. Si se hace segunda edición, el Diccionario del Habla Chilena, será corregido y aumentado por la Academia. No se podrá hacer una reimpresión, sino una segunda edición corregida y aumentada.

El Sr. Garretón expresó que hoy entregó a la Editorial, la mayor parte de las fichas, las demás se enviarán en el curso de la semana.

El Sr. Director, manifestó que en la primera prueba va a agregar lo que pueda y se podrán hacer las correcciones más necesarias. Expresó el Sr. Oroz que en este último tiempo, se han publicado en la prensa, algunos "glosarios" referentes a las industrias, a la cuprera, por ejemplo, y era necesario incluir estos vocablos en el "Diccionario del Habla Chilena"; aunque la mayoría son anglicismos, pero han sido castellanizados. (acta de sesión AChL, 06/08/1976)

redacción de un diccionario, en un momento en que ya iba tomando forma la concepción de la lexicografía como lingüística aplicada. Por esta razón, presumiblemente, fue nombrado relator de la Comisión de Lexicografía apenas se incorporó al equipo. Matus se sumaría al proyecto lexicográfico de Augsburgo algunos años más tarde (1978), y a través del entorno institucional de la U. de Chile (cf. Rojas 2015). En este marco, recibiría un entrenamiento acabado en las entonces más modernas técnicas y problemas teóricos de la lexicografía. Para el momento de redactarse el $D H C h$, todavía no contaba con esta formación hiperespecializada, así que no puede suponerse que haya tenido algún influjo en la elaboración del diccionario de la Academia Chilena. 
Es sorprendente lo tarde que se concretó la participación de una editorial, lo cual probablemente también provocó, junto con la necesidad percibida de hacer adiciones y correcciones de último momento, que, a pesar de todos los esfuerzos y de lo avanzado que parecía estar el trabajo, tampoco se lograra llegar a la imprenta con ocasión del congreso de academias. La obra se publicó finalmente con bastante retraso, en julio de 1978.

En conclusión, podemos apreciar que el proyecto lexicográfico académico impulsado a mediados del siglo XX tiene una relación de continuidad con el trabajo lexicográfico de colaboración subsidiaria con la RAE que se autoimpuso como misión primera la Academia Chilena en el momento de su fundación. Una manifestación evidente de esta relación de continuidad corresponde a que el proyecto del "Diccionario de chilenismos" surge como una prolongación de la tarea académica habitual de examinar y recomendar voces chilenas para su posible inclusión en una próxima edición del $D R A E$, que es precisamente el espíritu que subyace a la lexicografía chilena normativa de fines del siglo XIX (cf. Rojas 2010). De ahí que el DHCh, al momento de su publicación, se presente "al público en general y a la Real Academia Española en particular" (Academia Chilena 1978: 15; cursivas nuestras), y que, junto con incluir chilenismos ya registrados en el $D R A E$, se incluyan "numerosas voces y locuciones que tienen mucha circulación en Chile [...] que hasta el momento no han sido admitidas por la docta corporación española" (Academia Chilena 1978: 20).

Además, el $D H C h$ se proponía reunir "en un solo volumen el material lexicográfico de los diccionarios [de chilenismos] antiguos tras un examen crítico y selectivo" (Academia Chilena 1978: 17). Esto significa que el $D H C h$ no venía a cuestionar los fundamentos y la naturaleza de la tradición lexicográfica chilena precedente, sino más bien a ocupar su lugar, pues "con todos sus defectos metodológicos y deficiencias científicas, estas obras sobre 'chilenismos' son todavía hasta hoy de gran utilidad" (ibid.). Es decir, en palabras de Pedro Lira Urquieta, el DHCh "desea reemplazar los diccionarios ya existentes" (Lira 1973: 15; cursivas nuestras), refiriéndose a los diccionarios de chilenismos antiguos. Decir reemplazar no implica abolir el lugar que se ocupará, sino preservarlo.

Podemos, de este modo, pensar en el despliegue histórico del proyecto lexicográfico del $\mathrm{DHCh}$ no como un evento glotopolítico correspondiente de forma discreta a una etapa "de transición" posterior a (y desligada de) la de los diccionarios normativos de chilenismos anteriores a 1918, sino más bien como una continuación recontextualizada (es decir, sensible a un nuevo contexto) de un proyecto que tiene sus raíces en el clima lingüístico-ideológico en que la Academia comenzó su andadura a fines del siglo XIX. En el siguiente apartado nos dedicaremos a caracterizar cuál es ese nuevo contexto y a explicar cómo contribuye darle al $D H C h$ una nueva capa de sentidos glotopolíticos.

\section{Un nuevo contexto: la dictadura militar y la resignificación del $\mathrm{DHCh}$}

\subsection{La ASALE y los congresos de academias}

El nuevo escenario glotopolítico, que permite hablar de una recontextualización y resignificación del proyecto, tiene punto de partida en la emergencia, a mediados del siglo XX, de la Asociación de Academias de la Lengua Española (en adelante, ASALE), que forma parte integral del hispanismo impulsado por la diplomacia cultural española con especial brío desde fines del siglo XIX. 
Según Cortez y Gómez (2015: 9), el hispanismo del largo siglo XIX fue una respuesta discursiva a la crisis política, económica y cultural provocada por la desarticulación del Imperio español. Este proyecto pretendía articular una hegemonía cultural basada en el lugar preeminente de España en una comunidad imaginada, unitaria y supranacional, conformada por España y sus ex-colonias. La lengua compartida y las prácticas culturales asociadas a ella (literatura, religión, etc.) servirían de columna vertebral de esta comunidad; más específicamente, se otorgaba este rol a la norma estándar moldeada por los modelos literarios castellanos y encarnada en los códigos de la RAE (Del Valle y Gabriel-Stheeman 2004: 23-27).

En la iniciativa de la RAE de crear academias correspondientes en América desde 1870 confluyeron de forma cómplice los intereses de los agentes culturales del neocolonialismo español y las élites criollas americanas. Según Süselbeck (2014: 281), estas últimas vieron en el hispanismo una oportunidad para legitimar su posición privilegiada en las repúblicas hispanoamericanas, mediante la naturalización del privilegio concedido a sus formas de hablar (percibidas o imaginariamente construidas como más afines a la norma estándar que el habla de los sectores subalternos). Por parte de España, el beneficio buscado era, en palabras del académico mexicano Fermín de la Puente Apezechea, "reanudar los violentamente rotos vínculos de la fraternidad entre americanos y españoles; restablecer la mancomunidad de gloria y de intereses literarios [...]; y por fin, oponer un dique [...] al espíritu invasor de la raza anglo-sajona en el mundo por Colón descubierto" (cit. en Da Rosa 2014: 147). Junto con estos fines culturales y “espirituales", también debe tenerse en cuenta los beneficios económicos derivados del acrecentamiento del capital blando español (Del Valle 2007).

Si bien durante la primera mitad del siglo XX el proyecto de academias correspondientes recobró fuerza gracias a la fundación de nuevas corporaciones y la reactivación de varias de las ya existentes ( $\sin$ ir más lejos, la Academia Chilena reanudó sus actividades en 1914), el año de 1951 marca un hito crucial por la celebración en México del primer congreso de academias, que daría origen al nacimiento de la ASALE. La tónica de este encuentro fue el consenso "en torno a un discurso de moderado purismo -que aceptara la naturaleza cambiante de la lengua y la necesidad de adaptarte a los tiempos y a las circunstancias- y en torno a la defensa de la unidad del idioma basada en la acción coordinada de todas las academias" (Del Valle 2015: 270). Al mismo tiempo, hubo una prominencia especial de la idea (probablemente puesta de relieve por la ausencia de la RAE en el congreso ${ }^{7}$ ) de que "Latinoamérica estaba lista para intervenir en activamente en la gestión de un idioma que consideraban propio" (Del Valle 2015: 276), lo que en términos de planificación del corpus se traduciría en los propósitos de "enriquecer la lengua con palabras comúnmente usadas en Latinoamérica y definir con propiedad los americanismos ya incluidos en el diccionario de la RAE" (Del Valle 2015: 281).

En este mismo sentido, el mexicano Martín Luis Guzmán propuso reestructurar la jerarquía de la asociación sobre principios igualitarios, quitándole a la RAE su posición privilegiada, moción

7 La RAE, considerada por la mayoría de académicos como la líder natural de la ASALE, se marginó del congreso por requerimiento de la dictadura de Franco. Esta había puesto como condición para la participación española que el gobierno mexicano de Mateo Alemán suspendiera el reconocimiento diplomático del gobierno "rojo" (republicano) exiliado. México, sin embargo, mantuvo su desconocimiento de la legitimidad de la dictadura de Franco. Por esos años la España franquista buscaba ganar legitimidad ante la comunidad internacional, y por ello el evento de 1951 se le presentaba como una oportunidad inmejorable para contrarrestar el problema ocasionado por la decisión de México de sostener su rechazo al levantamiento de las sanciones impuestas por la ONU a España en 1946. 
que fue censurada por la gran mayoría de las academias participantes, incluida la chilena. Asimismo, el también mexicano Antonio Castro Leal propuso reestructurar las tareas lexicográficas académicas, elaborando un diccionario de americanismos y un nuevo diccionario general, idea que también contó con importantes resistencias por considerarse que amenazaba la unidad del idioma. Nuevamente, entre las academias que rechazaron esta moción lexicográfica se encontraba la Academia Chilena, aunque, de forma contradictoria, según Araneda Bravo (1976) en aquella ocasión Rodolfo Oroz (quien luego dirigiría el $D H C h$ ) "propuso la necesidad de formar un Diccionario de americanismos" (Araneda Bravo 1976: 67). En general, la postura de la Academia Chilena en los debates surgidos en el congreso de 1951 fue la de alineamiento con la RAE y los intereses hispanistas, lo que se puede ilustrar con las palabras pronunciadas por Pedro Lira (secretario de la corporación y luego también de la comisión encargada del $\mathrm{DHCh}$ ) en uno de estos debates: "Yo juzgo, y lo digo bien alto, que el meridiano del idioma pasa por Madrid" (cit. en Del Valle 2015: 280).

En fin: el relato historiográfico de la Academia Chilena acerca de su propio devenir (Araneda Bravo 1976), reconociendo implícitamente la importancia de este nuevo contexto, distingue como "cuarta época de la Academia" el periodo comprendido entre 1951 y 1976, año en que se celebró la séptima versión del congreso de academias, por primera vez en Santiago de Chile, cumpliéndose 25 años desde el congreso de México. De acuerdo con el prólogo del $\mathrm{DHCh}$, la Academia Chilena había sugerido en el congreso académico de 1951 que las correspondientes americanas emprendieran proyectos de diccionarios de dialectalismos nacionales (nótese la discrepancia con el reporte de Araneda Bravo, citado más arriba). El propio DHCh, de esta forma, establece su origen en el hito histórico de 1951, con lo cual la corporación chilena reinscribe su propia tarea lexicográfica, que venía desarrollándose desde fines del XIX, en el marco de los intereses de la nueva organización de academias, revitalizándolo a la vez que revalorizándolo en el marco del hispanismo académico.

\subsection{El congreso de academias de 1976 y la dictadura militar chilena}

La recontextualización a partir de los hitos históricos que se avecinaban: conmemoración del centenario de la lexicografía chilena monolingüe diferencial (1975) y la primera celebración de un congreso de academias en suelo chileno (1976), dan cuenta de los nuevos sentidos que cobró para sus propios autores. Y en este punto hay que mencionar el elefante en la habitación: la parte decisiva de la elaboración del $D H C h$, así como la celebración del congreso académico en Santiago, se dieron en el contexto de los primeros años de la dictadura militar encabezada por Augusto Pinochet, cuyo golpe de Estado del 11 de septiembre de 1973 había acabado violentamente con el gobierno socialista de la Unidad Popular, presidido por Salvador Allende.

Creo que debemos sospechar una solidaridad glotopolítica estrecha entre (1) la publicación del DHCh, (2) la celebración del séptimo congreso de academias en Chile y (3) la campaña de legitimación del gobierno de la dictadura militar. La relación entre (1) y (2) ya ha quedado clara: el diccionario como intervención glotopolítica fue resignificado por la Academia Chilena (sobre la base del proyecto original) como una obra conmemorativa del hito de celebrarse la primera reunión de academias en suelo chileno. Cabe luego preguntarse: ¿qué relación hay entre lo anterior y 
la legitimación de la dictadura militar? Para responder esta interrogante, hay que sacar a colación el rol del hispanismo en la política cultural de la derecha conservadora chilena, que incidió directamente en el proyecto de país de los militares.

El hispanismo es un proyecto vigente hasta hoy en las políticas lingüísticas oficiales el mundo hispanohablante; de hecho, en las últimas décadas, especialmente desde fines de la década de 1990, ha ganado todavía mayor fuerza y se ha premunido de un nuevo rostro gracias a la implantación de la Nueva Política Lingüística Panhispánica de la ASALE (Lauría y López 2009). No hay razones de peso para no pensar que se mantuvo vivo, aunque fuera de forma quizá menos prominente, durante las décadas anteriores a este crecimiento, siendo así un proyecto ubicuo a lo largo de todo el siglo XX y que por tanto tuvo la posibilidad de ser movilizado por y de influir en distintos proyectos políticos del mundo hispanohablante durante este periodo. En el caso chileno, la dictadura militar encabezada por Pinochet se vinculó con el hispanismo a través del rol de modelo que le asignó a la dictadura franquista y de la inspiración que la derecha chilena, actor civil relevante en la legitimación de la dictadura militar, encontró en la derecha conservadora española (Jara 2008).

El historiador chileno Jaime Eyzaguirre (1908-1968), en particular, fue una figura clave en la promoción del hispanismo en el Chile de mediados del siglo XX (Sagredo 2019). En su interpretación de la historia de Chile, Eyzaguirre "apeló [...] a la promoción y exaltación del legado histórico y cultural que España heredó a sus excolonias como fundamento del futuro" (Sagredo 2019: 192). Habiendo ya muerto al comenzar la dictadura militar, su obra, sin embargo, después de 1973 "cobró nuevos bríos y su figura se transformó en un referente de las nuevas autoridades" (Sagredo 2019: 196). No es de extrañar, en consecuencia, que la dictadura chilena pusiera de relieve las claves ideológicas hispanistas en el primer documento programático de su proyecto de nación, la Declaración de Principios del Gobierno de Chile, publicada el 11 de marzo de 1974. En este texto, la influencia del pensamiento político conservador de Eyzaguirre (al menos en la parte más temprana de la dictadura) es patente en sus dimensiones nacionalista, corporativista, católica e hispanista (Sagredo 2019: 202), como se puede colegir de sus menciones a "nuestra tradición cristiana e hispánica" como fundamento de la nueva sociedad y a la alusión a que "Chile tiene una larga tradición de organización social, que se remonta a su origen hispánico” (cit. ibid.).

El hispanismo chileno representado por Eyzaguirre encontró varios espacios institucionales idóneos para su articulación y organización durante la parte central del siglo XX. El principal fue el Instituto Chileno de Cultura Hispánica, fundado en 1948, sede local del Instituto de Cultura Hispánica, y por tanto representativo y continuador de la política neocolonialista e hispanista asociada al Consejo de la Hispanidad creado por el franquismo en 1940. En la corporación chilena, estaba asegurada una importante representación de intelectuales nacionales, en proporción paritaria respecto de los españoles; de hecho, el peso de la opinión del propio Eyzaguirre sobre el nivel central español aseguró una tendencia a mantener una tendencia culturizante (por oposición a politizante) en el nombramiento de integrantes del directorio y en sus líneas de acción, estrategia tendiente a evitar acusaciones de injerencia política extranjera en los asuntos nacionales (Cañellas Mas 2014: 79). Otro espacio institucional de desarrollo del hispanismo en Chile durante la segunda mitad del siglo XX fue la revista Estudios, de tendencia católica conservadora, fundada en 1932 por el mismo Eyzaguirre y dirigida por él hasta 1957, asociada al Centro de Estudios Religiosos. Finalmente, la Academia Chilena correspondiente de la Española, por su naturaleza intrínseca de agente de la diplomacia exterior española, también sirvió de espacio propicio para 
la difusión del hispanismo. De hecho, nuevamente, Jaime Eyzaguirre figura entre los integrantes de esta corporación, habiendo ocupado el sillón 15 de la Academia Chilena desde 1960 hasta su muerte en 1968. Otra figura importante, también vinculada con el Instituto y con la revista Estudios, fue el literato Roque Esteban Scarpa, quien ingresó a la Academia en 1951 y fue director de la misma entre 1980 y 1995.

Incluso considerando la firmeza con que estaba arraigado el hispanismo en Chile al caer el gobierno de la Unidad Popular, la dictura militar le otorgó un impulso aún mayor:

[A]l incluirlo [al hispanismo] en su discurso cultural, [la dictadura] puso a su servicio los recursos humanos y materiales, los aparatos propagandísticos y educacionales del Estado. Ello, por supuesto, les otorgó a dichos valores culturales una resonancia social desconocida en años anteriores, pues pasaron a formar parte de la política cultural pública y adquirieron la categoría de saber oficial. (Jara 2008: 236)

Manifestación de esto es, por ejemplo, la reorientación de la editorial estatal chilena Quimantú, que editó o reimprimió obras de connotados hispanistas españoles y chilenos, entre ellos Ramiro de Maeztu, Osvaldo Lira y Eyzaguirre, poniendo a circular sus ideas con renovado vigor (Jara 2008: 236). En el caso de Eyzaguirre, sus obras historiográficas principales fueron declaradas material didáctico en las escuelas chilenas, "con lo cual se esperaba que el hispanismo derivara en la interpretación oficial de la historia chileno-americana en los colegios" (Jara 2008: 236).

En los primeros años de la dictadura, lo que estaba en juego detrás del cultivo de la relación con España era la legitimación internacional del gobierno de la Junta Militar chilena. Por ello, esta desplegó un importante dispositivo diplomático exterior, que en España tuvo como principal escenario la embajada chilena en Madrid, por cuya iniciativa se consiguió tempranamente el apoyo de parte de la prensa (Agencia Efe, $A B C, E l$ Alcázar) y de prominentes políticos (entre los que sobresalen los presidentes Luis Carrero Blanco y Carlos Arias Navarro, así como el Duque de la Torre, militar e integrante de la RAE) para contrarrestar la imagen negativa que en el mundo se estaba levantando en torno al régimen de Pinochet (Jara 2008: 238-239). En 1975, los miembros de la Junta Militar, José Toribio Merino (almirante de la marina) y Augusto Pinochet (comandante en jefe del ejército), hicieron sendos viajes oficiales a España (este último a propósito de los funerales de Franco y la coronación del nuevo rey), con el fin de sostener la campaña de legitimación de la dictadura en el extranjero 8 .

Si ya en su viaje de 1975 Pinochet, a pesar de haber sido recibido por múltiples personajes de la oficialidad española, "palpó directamente su aislamiento internacional" (Jara 2008: 240), en 1976, con la muerte de Franco y el cambio de gobierno, la actitud oficial de España hacia Chile se hizo menos favorable, pues "la legitimación del proceso de apertura [de España] ante Europa exigiría,

8 En este viaje, Merino fue acompañado de una delegación conformada entre otros por el escritor y miembro de la Academia Chilena, Enrique Campos Menéndez, conocido colaborador de la dictadura, como veremos más adelante. De acuerdo con el informe de Enrique Campos Menéndez, "[1]a reunión del Almirante Sr. Merino, perfeccionó el acuerdo cultural entre España y Chile, realizado en el Gobierno del Sr. Frei, que no se ha puesto en vigencia" (acta de sesión AChL, 07/04/1975), y "hubo un cambio de ambiente favorable a Chile, después de la visita del Sr. Almirante Merino, en España" (ibid.), lo cual se manifestaría tangiblemente en la asignación de numerosas becas de posgrado en España para chilenos por parte del Instituto de Cultura Hispánica, así como en el compromiso de fomentar la industria editorial chilena mediante la visita de editores españoles. 
además del distanciamiento del franquismo, su alejamiento de la dictadura chilena" (Jara 2008: 240). De este modo, a partir de esa fecha, las relaciones de España con Chile "se concentraron en la dimensión de asistencia técnica y comercial y muchos puntos del convenio cultural acordado cayeron en el vacío" (Jara 2008: 242), cuestión que se agravó todavía más con el voto contra Chile que España emitió en la ONU en 1978.

Podemos ver, entonces, que el hispanismo y el cultivo de la relación con España tenían una importancia política fundamental para la dictadura militar chilena, en particular durante sus primeros años. No parece casual, de este modo, que precisamente en ese momento se haya preparado y realizado en suelo chileno un encuentro académico articulado en torno a la celebración del hispanismo lingüístico. El congreso académico de 1976 puede interpretarse también como un evento glotopolítico funcional a los esfuerzos de la dictadura chilena por cultivar buenas relaciones diplomáticas no solo con España, sino también con los demás países hispanohablantes9. No por nada, según consta en el periódico santiaguino La Tercera (16/11/1976, pág. 11) el propio Augusto Pinochet presidió la inauguración de este congreso, celebrada en el edificio Diego Portales, sede del gobierno en ese momento ${ }^{10}$. El respaldo político oficial de la dictadura chilena al congreso de academias por realizarse en 1976 quedó así manifestado de forma inequívoca, y podemos sospechar que las razones de este respaldo caen por su propio peso a partir de la consideración de la importancia del hispanismo para la dictadura en esos primeros años ${ }^{11}$. El apoyo

9 Solo Cuba y México se restaron de participar, el primero por razones obvias y el segundo por la simpatía que el gobierno de Luis Echeverría Álvarez había manifestado por el socialismo chileno de Allende. Recuérdese además que el gobierno mexicano había concedido asilo político a la esposa de Allende, Hortensia Bussi, tras el golpe de Estado de los militares. La tensión diplomática entre Chile y México también se deja ver en la discusión que surgió en la Academia Chilena a propósito de la invitación extendida por la Academia Mexicana a la celebración de su primer centenario, en 1975. En la reunión del 7 de abril se informó de dicha invitación, ante la cual se acordó que el director, Oroz, se entrevistaría con el ministro de Relaciones Exteriores para ver si no habría algún inconveniente diplomático, y que el secretario tendría una conversación similar con el embajador venezolano en Chile, a la sazón encargado de los asuntos de México en el país. En la reunión del 21 de abril, el secretario informó de la venia del Ministerio de Relaciones Exteriores chileno, concedida por tratarse de un congreso "de carácter cultural". Finalmente la delegación chilena no asistió a la celebración, debido a que no se consiguió emitir a tiempo los visados correspondientes (acta de reunión del 1 de septiembre de 1975). No podemos saber a ciencia cierta si lo siguiente tuvo que ver con lo anterior, pero el director de la Academia Mexicana, Agustín Yáñez, solicitó (sin éxito) a la Comisión Permanente y a la RAE realizar el congreso de 1976 en México en lugar de en Chile, para así poder celebrar el centenario de la corporación mexicana.

10 La resonancia política de esta sede motivó una interesante discusión dentro de la Academia, en la que Luis Sánchez Latorre manifestó sus reservas, debidas a que al escoger dicho lugar "el Congreso quedaría totalmente identificado con el Gobierno" (acta de sesión AChL, 10/05/1976) (“Querámoslo o no, el Diego Portales es la imagen política del Gobierno” [ibid.], declaró), lo cual se opone al deseo de que "la Academia tiene que ser independiente" (ibid.). Frente a esto, Garretón y Oroz respondieron que su reserva era injustificada y que no creían que esto afectara a la neutralidad política deseada para el evento, y que además era el mejor lugar en términos logísticos. También, en una forma muy particular, expresó sus reservas el secretario Fidel Araneda Bravo: "Monseñor Araneda afirma que, por este camino medio dictatorial, teme que lleguen muy pocos académicos al Diego Portales. Eugenio Pereira afirma que las palabras de monseñor Araneda son muy poco cristianas. Monseñor Araneda rechaza la afirmación del Sr. Pereira y asegura que sus palabras nada tienen que ver con el cristianismo" (ibid.).

11 Debe tenerse en cuenta, no obstante, que la idea de realizar el congreso en Chile es anterior a la dictadura, pues sabemos que la sede para 1976 había quedado ya establecida en el congreso académico de 1972, celebrado en Venezuela, y que este ofrecimiento había tenido apoyo del Gobierno chileno, por ese entonces el de la Unidad Popular (Araneda Bravo 1976: 85). Habrá que pensar, entonces, que se trata de una "exaptación” glotopolítica, es decir, que la dictadura se aprovechó de la circunstancia en pos de sus propios fines, sobre todo porque la preparación misma del congreso comenzó tan solo en diciembre de 1973 (si hacemos caso de la "Crónica de la Academia - 1972-1973" adjunta al acta de sesión AChL, 05/06/1975) o en 1974 (si le creemos a Araneda Bravo 1976: 86). El programa definitivo del encuentro se difundió en marzo de 1975 (memoria de actividades 1975, adjunta a acta de sesión AChL, 01/12/1975) 
gubernamental se concretó, por lo demás, en aportes pecuniarios. La comisión encargada de la organización del congreso informaba que "se ha solicitado al Supremo Gobierno: 1) la suma de 50 mil dólares para pasajes y gastos de habitación de los concurrentes invitados; 80 millones de escudo para pagos de organización, contratación de funcionarios, pago de secretaría, etc." (acta de sesión AChL, 21/07/1975), lo cual finalmente fue concedido por las autoridades, aunque no sin algunos tropiezos ${ }^{12}$.

No puede omitirse, por otra parte, que en las buenas relaciones entre la Academia Chilena y la dictadura debió haber influido la presencia en la primera de una buena cantidad de intelectuales hispanistas durante esos años, entre ellos el mismo Eyzaguirre (muerto en 1968) o el ya mencionado literato Roque Esteban Scarpa. Asimismo, en sus filas contó con intelectuales orgánicos de la dictadura, como el escritor Enrique Campos Menéndez, conocido por ser asesor cultural oficial del régimen y amigo personal de Pinochet, además de furibundo hispanista (e integrante del Instituto de Cultura Hispánica); fue nombrado miembro de número de la Academia en $1976^{13}$. Finalmente, no es un dato en absoluto menor que entre los miembros de la Academia figuraran tanto el embajador de España en Chile, Emilio Baladiez (en la condición de miembro honorario, de nuevo, en 1976), como el ex comandante en jefe de la Fuerza Aérea chilena y miembro del Consejo de Estado de la dictadura (amén de escritor), Diego Barros Ortiz. Este último, además de formar parte de la mesa directiva de la Academia (en el cargo de censor, entre 1976 y 1978), integró la comisión encargada de redactar el DHCh, como vimos.

Cabe también destacar que la comisión organizadora del congreso estuvo integrada, entre otros, por Roque Esteban Scarpa, Enrique Campos Menéndez, Alejandro Garretón Silva y Diego Barros Ortiz (estos dos últimos, también involucrados en la comisión encargada del $D H C h$, y el primero uno de sus principales impulsores, como atestiguamos), a quienes, después de realizado el encuentro, agradeció efusivamente el director Oroz: "Ellos, dijo, hicieron el congreso, sin su intervención no habría sido posible realizarlo en la forma que se celebró" (acta de sesión AChL, 06/12/1976). Garretón respondió que sus desvelos se debieron a que "el Congreso llevaba envuelta la imagen de Chile en el exterior que a él le preocupaba mucho" (ibid.).

12 El director Oroz informó de su visita al ministro de Educación, el contralmirante Hugo Castro Jiménez (estrecho colaborador del almirante Merino), en la que expresó el deseo de la corporación por "saber si podía contar definitivamente con la ayuda del Gobierno" (acta de sesión AChL, 12/05/1975) para la organización del congreso. Considerados la cantidad de delegados y la duración, "al señor Ministro le pareció un desembolso muy grande" (ibid.), y propuso esperar hasta septiembre u octubre de ese año, cuando se haría el presupuesto para el año siguiente, pues de verse obligado a dar una respuesta en ese mismo momento "tendría que contestar negativamente" (ibid.). Una reacción reveladora fue la indignación de Alejandro Garretón, entonces tesorero de la corporación e integrante de la comisión organizadora del congreso, quien afirmó que "no podemos esperar [...] porque la situación de Chile en el exterior sufriría menoscabo si el Congreso no se efectúa" (ibid.). Al mes siguiente asumió un nuevo ministro, el contralmirante Arturo Troncoso Daroch, quien, en reunión sostenida con Garretón y Juvenal Hernández, "en lo que respecta al próximo Congreso de Academias en Chile, aseguró la realización del mismo y que se podía contar plenamente con su apoyo, por tratarse de un compromiso del Gobierno y por las graves consecuencias que se derivarían de no efectuarse como se ha previsto" (acta de sesión AChL, 16/06/1975).

13 No debe exagerarse, en cualquier caso, la aceptación de su presencia en la institución. A propósito de una ácida polémica interna en que Campos Menéndez fue acusado de plagiador por Roque Esteban Scarpa, el académico Luis Sánchez Latorre declaró haber "manifestado siempre que el gran impedimento del señor Campos para ser académico de número [en este momento académico correspondiente] es su carácter de funcionario de un Gobierno, y todo Gobierno, máxime uno autoritario, a él lo sobrecoge" (acta de sesión AChL, 10/11/1975). 
Precisamente de esto se trataba todo este despliegue de intervenciones glotopolíticas: de la imagen de Chile (de la dictadura militar) en el exterior ${ }^{14}$. En consideración de la articulación entre estas instituciones, personajes y proyectos político-culturales, no parece gratuito el tono optimista con que la Academia Chilena, en su relato oficial (y concebido para ser presentado a los asistentes al evento académico), caracteriza el estado del país en el momento de la celebración del congreso de 1976:

\begin{abstract}
Al llegar la Academia a su mayor auge y prestigio, Chile también ha adquirido una fisonomía propia, inconfundible [...]. Se han fundado varias universidades y éstas aumentan considerablemente; la prensa es una institución nacional, en cierto modo el cuarto poder del Estado; las industrias nacionales y extranjeras crecen por doquier; la capital es una urbe que no le va a la zaga a las mayores de América y Europa y lo mismo sucede con las demás ciudades; el nivel de vida y el desarrollo social y la madurez cívica son dignas de admiración del mundo entero; es la República hispanoamericana donde más ha imperado la democracia. Sólo accidentalmente se ha suspendido su ejercicio. (Araneda Bravo 1976: 86)
\end{abstract}

\title{
4. Conclusión
}

Para recapitular, hasta ahora he intentado mostrar que el $\mathrm{DHCh}$ adquiere su sentido glotopolítico fundamental en relación con la celebración del congreso de academias de Santiago de 1976, fecha y ocasión para las cuales se previó originalmente su publicación. El congreso de academias, a su vez, cobra significado como evento glotopolítico en cuanto, aunque gestado unos pocos años antes, es utilizado por la dictadura militar chilena en el poder desde 1973 como parte de su estrategia de legitimación en el extranjero. Si esto es posible es porque la dictadura chilena, mirándose en el espejo del franquismo, asumió el hispanismo como una de las matrices cultural fundamentales de su proyecto de refundación de la nación, y porque el hispanismo es precisamente el gran proyecto cultural en el que se inscribe la existencia y acción de las academias de la lengua.

De este modo, el $\mathrm{DHCh}$, originado en un proyecto lexicográfico de carácter fundamentalmente hispanista (colaboración de la Academia Chilena con el diccionario de la RAE), mediante esta

14 Como dato adicional pero crucial para comprender el alcance del rol colaborador de varios miembros de la Academia Chilena en el proyecto de legitimación de la dictadura, considérese lo siguiente: "El señor Martín Panero [sacerdote español radicado en Chile, miembro correspondiente de la Academia Chilena], dice que en la ESTAFETA LITERARIA, una de las mejores revistas españolas, número correspondiente al $1^{\circ}$ de noviembre de 1974, se afirma que en Chile hay trescientos campos de concentración, por los cuales han pasado trescientos mil chilenos y tendrán que pasar ochocientos mil. Rogó al Sr. Campos Menéndez que interpusiera un influjo para que se rectifiquen estos errores” (acta de sesión AChL, 07/04/1975). Otro ejemplo, menos transparentemente político por interponer la faz cultural como superficie de expresión de la cuestión política: “A propósito del Día de Cervantes, el Hermano Martín Panero dice que los diarios españoles dieron la noticia de que la Junta Militar chilena ha eliminado de la enseñanza el estudio del Quijote, sobre este particular hubo un largo debate, en el cual participaron los académicos señores Panero, Campos Menéndez, Silva, Arteche, Aldunate, Garretón y Barros. Se habló de la semana de Cervantes organizada por el Gobierno y de que el Sr. Campos Menéndez acompañara al Sr. Almirante Merino en un viaje a España con el objeto de intensificar las relaciones culturales entre nuestro país y la patria del autor del Quijote. El Sr. Barros Ortiz, propuso que se enviara una nota al Ministerio de Relaciones Exteriores de Chile, para manifestar que aquí se enseña y se exalta el Quijote, y a fin de hacer ver la injusticia de esta campaña en la cual se hacer aparecer al Gobierno de nuestro país como enemigo de Cervantes y de su obra. Así se acordó" (acta de sesión AChL, 06/01/1975). 
cadena de contextualizaciones se reviste también de este sentido legitimador de la dictadura, al ser objeto de una exaptación ${ }^{15}$ glotopolítica para formar parte del dispositivo desplegado por el gobierno de la Junta Militar chilena para mejorar su imagen y relaciones internacionales, especialmente con España. De ello da cuenta la sinergia de instituciones, actores involucrados e iniciativas que hemos identificado, las que actuaron concertadamente con el fin de impulsar el éxito de estas intervenciones glotopolíticas solidarias entre sí. Aunque no se pueda encontrar una sola referencia directa a la legitimidad de la dictadura en el texto mismo del $\mathrm{DHCh}$ (lo cual es explicable a la luz de la ansiedad por evitar acusaciones de politización que según hemos visto son recurrentes en la Academia Chilena), sí es posible en cambio identificar una representación de las variedades del castellano habladas en Chile (el "habla chilena" del título) estrechamente compatible con el hispanismo y con el proyecto de nación de la dictadura. Se trata, por su sentido político, de una ideología lingüística (Del Valle y Meirinho-Guede 2016) que ofrece la posibilidad de ser movilizada con el propósito en cuestión.

Una buena parte del "Prólogo" del $D H C h$ está dedicado a discutir la inconveniencia de adoptar el concepto de chilenismo característico de la tradición lexicográfica que le precede. Como vimos, la Academia Chilena optó por distanciarse de este concepto, sobre todo por las dificultades metodológicas de determinar lo que es "propio y privativo del español de Chile", es decir, la diferencia específica del "habla chilena". El discurso acerca de la particularidad dialectal puede leerse, en este punto, como un discurso acerca de la identidad chilena. Diversos pasajes del prólogo muestran un esfuerzo (de lo cual el $\mathrm{DHCh}$ habría que tomar como prueba) por comprobar que "lo que es exclusivamente nuestro en materia de léxico es mucho más exiguo que lo que nos imaginábamos en un principio" (Academia Chilena 1978: 19), y que existen muchas más convergencias que divergencias lingüísticas con España y los demás países hispanohablantes ${ }^{16}$. La Academia reconoce que los indigenismos podrían ser "el único acervo seguro que nos pertenece con propiedad de manera exclusiva" (Academia Chilena 1978: 17), para a renglón seguido indicar que "sólo una pequeña parte posee real vitalidad hoy día" (ibid.), y que, aún más, son empleados más en la literatura criollista que en la tradición oral popular (Academia Chilena 1978: 17-18); es decir, su uso, además de minoritario, es ficticio.

De forma crucial, la Academia Chilena sigue el concepto de chilenismo establecido por Rabanales (1953), es decir, se basa en un criterio de origen para su definición: independiente de si se use de forma exclusiva en Chile, una palabra no será chilenismo si no tiene origen en Chile (Academia Chilena 1978: 18). El factor determinante es la "prioridad en el uso" (Academia Chilena 1978: 19), lo cual quiere decir prioridad histórica: lo importante es de dónde proviene la palabra. Al poner el origen en el centro de la caracterización de los chilenismos, el DHCh ofrece un espacio de legitimación para los discursos que, en el ámbito de la política cultural y de la definición de la nación, por esas mismas fechas planteaban una identidad nacional chilena sobre la base de la herencia

15 Uso los términos exaptar y exaptación inspirándome en el sentido que se les dio originalmente en ciencias naturales y que luego fue también utilizado en la lingüística histórica (cf. Lass 1990): la utilización de algo con un fin al que no estaba originalmente destinado.

16 Así, por ejemplo, cuando se indica que hay una cantidad considerable de voces incluidas en el $D H C h$ que son "tan propias de nuestro país como de ciertas provincias de España" (Academia Chilena 1978: 19), o cuando, al hacer una caracterización general de la fonología y morfología del "habla chilena", se afirma que el rotacismo y lambdacismo se da en Chile "igual que en el habla popular de Extremadura y Andalucía” (Academia Chilena 1978: 23). 
española, es decir, sobre una matriz hispanista. Recuérdese que los chilenismos "verdaderos" son en realidad muy pocos, según el $\mathrm{DHCh}$, lo que tendría como correlato que el habla chilena en realidad sea fundamentalmente, castellana; y en cuanto a la nación chilena, esto querría decir que, a pesar de todo, los chilenos somos esencialmente españoles en América. Dicha representación ideológica del lenguaje contribuye, como se deduce de lo que hemos señalado durante este trabajo, a los propósitos e intereses políticos de la amplia gama de agentes sociales que participaron en la gestación y difusión del $\mathrm{DHCh}$.

\section{Referencias bibliográficas}

\section{Fuentes primarias}

Academia Chilena, libros de actas 1885-1995 (inéditos). Instituto de Chile.

Academia Chilena (1978). Diccionario del habla chilena. Santiago: Editorial Universitaria.

Araneda Bravo, F. (1976). La Academia Chilena correspondiente de la Real Española e integrante del Instituto de Chile. Santiago: Editorial Universitaria.

“Dijo el académico Rodolfo Oroz: 'Ya no existen fantasmas que amenacen el idioma español”, La Tercera, 16/11/1976, pág. 11 .

\section{Bibliografía secundaria}

Ayala Pérez, T. (2011). Ambrosio Rabanales y el español de Chile: una aproximación a los conceptos de norma y de chilenismo. Boletín de Filología, 46, 2, 199-218.

Bourdieu, P.; \& Boltanski, L. (2009). La producción de la ideología dominante. Trad. H. Cardoso. Buenos Aires: Nueva Visión.

Calero Fernández, M. Á. (1999). Diccionario, pensamiento colectivo e ideología (o los peligros de definir). In M. Vila et al. (Eds.), Así son los diccionarios (pp. 149-201). Lleida: Universitat de Lleida.

Cañellas Mas, A. (2014). Las políticas del Instituto de Cultura Hispánica, 1947-1953. Historia Actual Online, $33,77-91$.

Chen, W. (2019). Towards a discourse approach to Critical Lexicography. International Journal of Lexicography, 32, 3, 362-388.

Cortez, E.; \& Gómez, L. (2015). Hispanismo y hegemonía en las Américas. Una introducción. Revista de Crítica Literaria Latinoamericana, 82, 9-20.

Da Rosa, J. J. (2014). Los nuevos guardianes del buen decir en el siglo XIX. Monarquía de la Restauración y Academias de la Lengua. In M. Coll, \& M. Barité (Eds.), Aspectos de lexicografía teórica y práctica: una mirada desde el Río de la Plata (pp. 147-165). Montevideo: Universidad de la República.

Del Valle, J. (Ed.) (2007). La lengua, ¿patria común? Ideas e ideologías del español. Frankfurt/Madrid: Vervuert/Iberoamericana. 
. (2015). La emancipación lingüística y las academias de la lengua española en el siglo XX: 1951 como punto de inflexión. En J. del Valle (Ed.), Historia política del español. La creación de una lengua (pp. 266-286). Madrid: Aluvión.

- (2017). La perspectiva glotopolítica y la normatividad. Anuario de Glotopolítica, 1, 17-39.

Del Valle, J.; \& Gabriel-Stheeman, L. (2004). Nacionalismo, hispanismo y cultura monoglósica. In J. del Valle, \& L. Gabriel-Stheeman (Eds.), La batalla del idioma. La intelectualidad hispánica ante la lengua (pp. 15-33). Frankfurt/Madrid: Vervuert/Iberoamericana.

Del Valle, J.; \& Meirinho-Guede, V. (2016). Ideologías lingüísticas. In J. Gutiérrez-Rexach (Ed.), Enciclopedia de lingüística hispánica (vol. 2) (pp. 622-631). London \& New York: Routledge.

Forgas, E. 2011. El compromiso académico y su reflejo en el DRAE: los sesgos ideológicos (sexismo, racismo, moralismo) del Diccionario. In S. Senz, \& M. Alberte (Eds.), El dardo en la Academia: esencia y vigencia de las academias de la Lengua española (vol. II) (pp. 425-457). Santa Cruz de Tenerife: Melusina.

Huisa, J. C. (2013). La impronta política en la primera lexicografía hispanoamericana: republicanismo y antirrepublicanismo. Lexis, 37, 2, 269-303.

Jara, I. (2008). La ideología franquista en la legitimación de la dictadura militar chilena. Revista Complutense de Historia de América, 34, 233-253.

Lass, R. (1990). How to Do Things with Junk: Exaptation in Language Evolution. Journal of Linguistics, 26, $1,79-102$.

Lauria, D. (2011). Apuntes para una historia de la producción lexicográfica monolingüe en la Argentina: etapas del proceso de diccionarización y modalidades diccionarísticas entre 1870 y 1910. Boletín de Filología, $46,1,106-150$.

Lauria, D.; \& López García, M. (2009). Instrumentos lingüísticos académicos y norma del español: la nueva política lingüística panhispánica. Lexis, 33, 1, 49-89.

Lira, P. (1973). Estudios sobre vocabulario. Santiago: Editorial Andrés Bello.

Matus, A. (1994). Períodos de la lexicografía diferencial del español de Chile. In Actas del X Congreso de la Asociación de Academias de la Lengua Española (pp. 189-199). Madrid: RAE/Espasa Calpe.

Morales Pettorino, F. (dir.); \& Quiroz, O. (1983-1987). Diccionario ejemplificado de chilenismos y otros usos diferenciales del español de Chile. 4 vols. + Estudio preliminar y Suplemento y bibliografía. Santiago: Editorial Universitaria.

Moré, B. (2014). Lengua y poder en la obra gramatical de Andrés Bello. Caracas: Fundación Casa Nacional de las Letras Andrés Bello.

Ortúzar, C. (1893). Diccionario manual de locuciones viciosas y de correcciones del lenguaje con indicación del valor de algunas palabras y ciertas nociones gramaticales. San Benigno Canavese: Imprenta Salesiana.

Rabanales, A. (1953). Introducción al estudio del español de Chile. Determinación del concepto de chilenismo. Santiago: Editorial Universitaria.

Rodríguez Barcia, S. (2008). La realidad relativa. Evolución ideológica en el trabajo lexicográfico de la Real Academia Española (1726-2006). Vigo: Universidade de Vigo.

- (2016). Lexicografía crítica. In Introducción a la lexicografía (pp. 255-302). Madrid: Síntesis.

Rodríguez, Z. (1875). Diccionario de chilenismos. Santiago: Imprenta de El Independiente.

Rojas, D. (2010). Estandarización lingüística y pragmática del diccionario: forma y función de los 'diccionarios de provincialismos' chilenos. Boletín de Filología, 45, 1, 209-233. 
. (2015). Ambrosio Rabanales y el proyecto lexicográfico de Augsburgo: el inconcluso "Nuevo diccionario de chilenismos". Ponencia leída en el coloquio "El Archivo Ambrosio Rabanales: un nuevo testimonio para la historia de la lingüística en Chile", 20 de agosto de 2015, Universidad de Chile.

. (2016). The Chilean Academy of the Spanish Language: the institutionalization of a discourse community. History and Philosophy of the Language Sciences. <https://hiphilangsci.net>

. (2017). Representaciones del cambio lingüístico en Chile durante el siglo XIX: ‘'progreso o decadencia?.' Literatura y Lingüística, 36, 243-262.

. (2019). El hispanismo en los orígenes de la Academia Chilena de la Lengua: Vicente Pérez Rosales frente a Zorobabel Rodríguez (1885). Quo Vadis, Romania?, 53-54, 20-41.

Rojas, D.; \& Avilés, T. (2014). Ideologías lingüísticas en la fraseología del español de Chile: dos momentos, una misma concepción del lenguaje. Onomázein, 29, 64-77.

Román, M. A. (1901-1918). Diccionario de chilenismos y de otras locuciones viciosas. Santiago: Imprenta de San José.

Sáez Godoy, L. (1982). Algunas observaciones sobre el diccionario más reciente del español de Chile: el Diccionario del Habla Chilena (DHCh). Estudios Filológicos, 17, 111-124.

- (1987-1988). A propósito del Diccionario del Habla Chilena. Literatura y Lingüística, 1, 107-127.

Sagredo, R. (2019). Jaime Eyzaguirre y la circulación del hispanismo en Chile. História Unisinos, 23, 2, 191 203.

San Vicente, F.; Garriga, C.; \& Lombardini, H. E. (Coords.) (2011). Ideolex. Estudios de lexicografía e ideología. Monza: Polimetrica.

Süselbeck, K. (2014). Las Academias Correspondientes de la Lengua en la Hispanoamérica del siglo XIX. In S. Carreras, \& K. Carrillo Zeiter (Eds.), Las ciencias en la formación de las naciones americanas (pp. 271-294). Madrid/Frankfurt: Iberoamericana/Vervuert.

This work can be used in accordance with the Creative Commons BY-SA 4.0 International license terms and conditions (https://creativecommons.org/licenses/by-sa/4.0/legalcode). This does not apply to works or elements (such as images or photographs) that are used in the work under a contractual license or exception or limitation to relevant rights. 